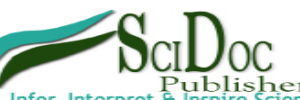

International Journal of Forensic Science \& Pathology (IJFP)

ISSN 2332-287X

\title{
Variant Translocation of ETV6 and RUNX1 in a Case of Pediatric Acute Lymphoblastic Leukemia
}

Yenamandra $\mathrm{A}^{1 *}$, Hollis $\mathrm{A}^{1}$, McManus $\mathrm{M}^{2}$

Editorial

${ }^{1}$ Department of Pathology, Microbiology and Immunology, Vanderbilt University Medical Center, Nashville, TN, USA.

${ }^{2}$ Department of Medicine, Division of Hematology and Oncology, Erlanger Medical Center, Chattanooga, TN, USA.

*Corresponding Author:

Ashwini Yenamandra,

Department of Pathology, Microbiology and Immunology, Vanderbilt University Medical Center, Nashville, TN, USA.

E-mail: ashwini.yenamandra@vanderbilt.edu

\section{Recieved: July 25, 2015}

Published: August 19, 2015

Citation: Yenamandra A, Hollis A, McManus M (2015) Variant Translocation of ETV6 and RUNX1 in a case of Pediatric Acute Lymphoblastic Leukemia. Int J Forensic Sci Pathol. 3(2e), 1-2. doi: http:/ /dx.doi. org/10.19070/2332-287X-150004e

Copyright: Yenamandra $\mathbf{A}^{\mathcal{C}}$ 2015. This is an open-access article distributed under the terms of the Creative Commons Attribution License, which permits unrestricted use, distribution and reproduction in any medium, provided the original author and source are credited.

Rearrangement of ETV6 (or TEL) gene at chromosome 12p13 region has been reported in several hematopoietic malignancies. About $25 \%$ of pediatric B cell Acute Lymphoblastic leukemia (BALL) cases have $\mathrm{t}(12 ; 21)$ translocation involving ETV6 locus at $12 \mathrm{p} 13$ and RUNX1 locus at 21q22 $(1,2)$ and is associated with a good event free survival. Many of these cases may have additional aberrations in addition to poor morphology. Variant and complex translocations of $\mathrm{t}(12 ; 21)$ involving an additional chromosome have been reported in several cases of ALL [1-6].

We report a case of a 2- year old male referred in May of 2013 for lymphocytosis, anemia, and thrombocytopenia. He had notable petechiae and bruising. His white cell count was 16,000, hemoglobin $8.7 \mathrm{~g} / \mathrm{dL}$, platelet count of 116,000 and neutrophil count of 500. Flow Cytometry revealed immature B cell population with $76 \%$ of abnormal B lymphoblasts with L2 morphology, positive for CD10, CD19, CD34, CD58, negative for CD20 and decreased in expression for CD 38 and CD 45. These findings were consistent with precursor B cell lymphoblastic leukemia.

Bone marrow cells of the patient were cultured and chromosome preparations were made the following day. Twenty Giemsabanded metaphase spreads were analyzed by standard cytogenetic techniques. Fluorescence in situ hybridization (FISH) was performed on both interphase and metaphase cells of the bone marrow using the standard FISH procedure with dual color RUNX1 spectrum orange and ETV6 Spectrum green probes (Abbott Molecular, DownersGrove, IL). Two hundred interphase nuclei were analyzed through an Olympus BX61 fluorescent microscope attached to a CCD camera and Genetix (Applied Imaging, Pittsburgh, PA).

FISH with ETV6/RUNX1 probe revealed an ETV6/RUNX1 fusion signal on abnormal chromosome 21, wild type green ETV6 and red RUNX1 signals were localized to normal chromosome $12 \mathrm{p}$ and $21 \mathrm{q}$ respectively. The residual small red RUNX1 signal was localized on chromosome 11 at p15 region. This was identified through sequential FISH hybridization of the same metaphases that were also karyotyped (Figures. 1-6). Rearrangement of RUNX1 with $11 \mathrm{p} 15$ region resulted in a variant and complex $\mathrm{t}(12 ; 21)$ translocation involving chromosome 11. Karyotype is described as 46, XY, t(11;12;21) (p15;p13;q22) [2]/46, XY [18].

Although the clinical significance of variant translocations is unclear in some cases, our patient is clinically doing well, being treated on study AALL1131, high risk arm, currently in mainte-

Figure 1. Karyotype 1.

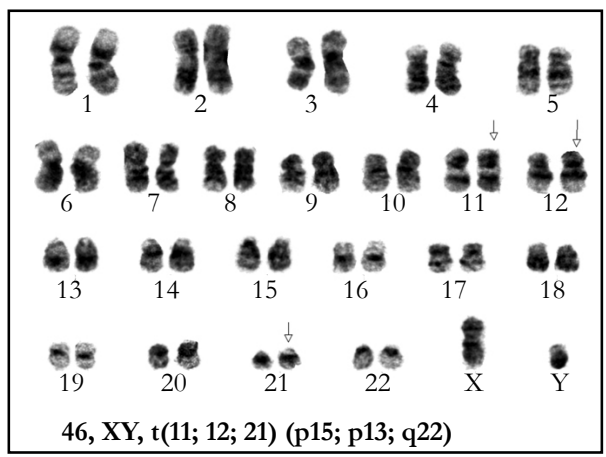


Figure 2. Sequential FISH on Metaphase 1.

Figure 3. Metaphase 1.
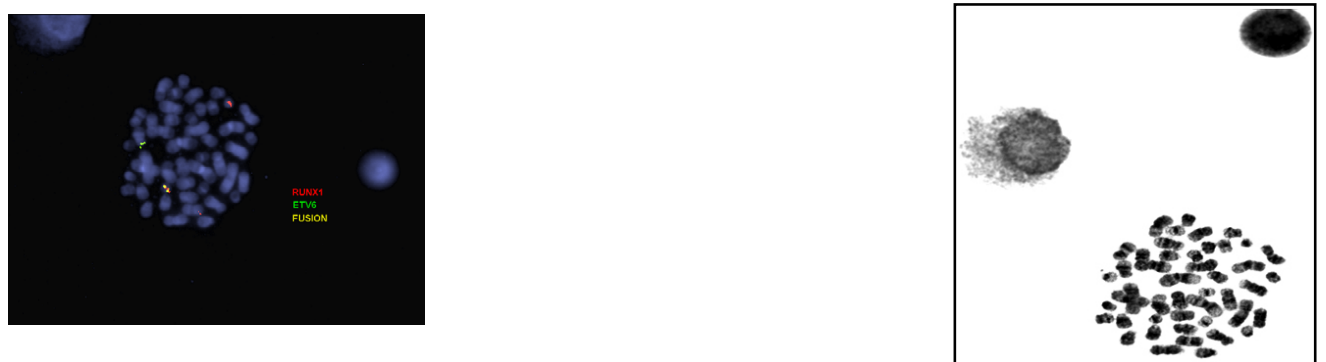

Figure 4. Karyotype 2.

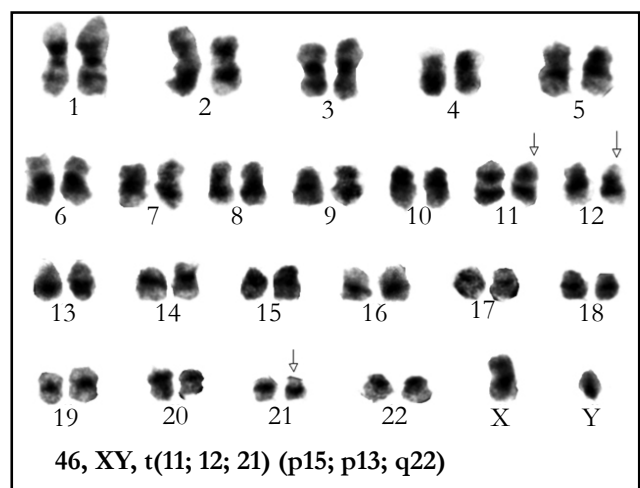

Figure 5. Sequential FISH on Metaphase 2.

Figure 6. Metaphase 2.
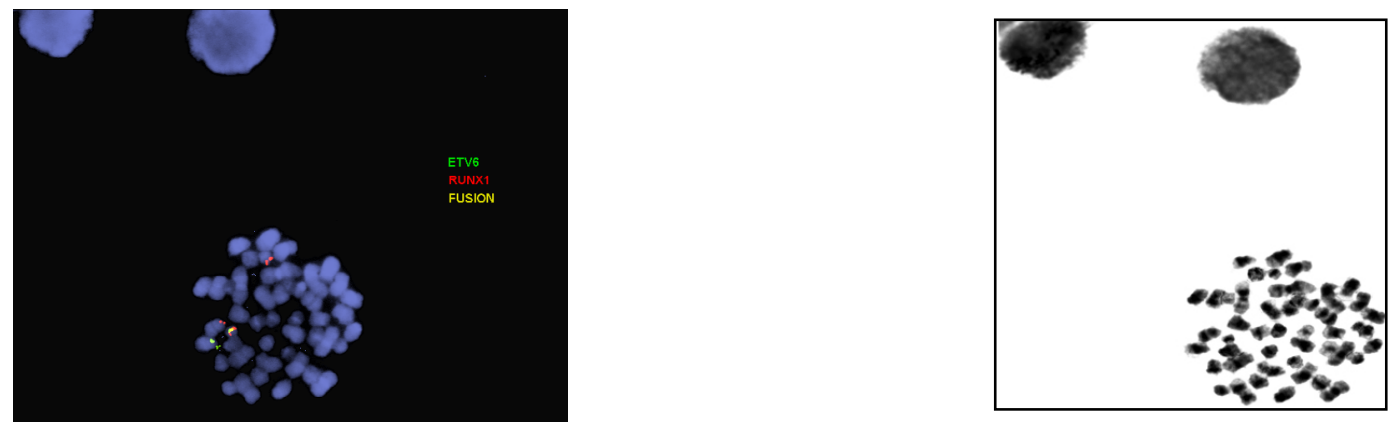

nance therapy.

\section{References}

[1]. Mathew S, Shurtleff SA, Raimondi SC (2001) Novel Cryptic, Complex Rearrangements Involving ETV6-CBFA2 (TEL-AML1) Genes Identified by Fluorescence In Situ Hybridization in Pediatric Patients With Acute Lymphoblastic Leukemia. Genes Chromosomes Cancer 32(2): 188-193.

[2]. Raimondi SC (1993) Current status of cytogenetic research in Childhood acute lymphoblastic leukemia. Blood 81(9): 2237-2251.

[3]. Mitelman F (1994) Catalog of Chromosome Aberrations in Cancer. (5th edtn), Wiley-Liss, New York.
[4]. Gandemer V, Chevret S, Petit A, Vermylen C, Michel G, et al. (2012) Excellent prognosis of late relapses of ETV6/RUNX1-positive childhood acute lymphoblastic leukemia: lessons from the FRALLE 93 protocol. Haematologica 97(11): 1743-1750.

[5]. Forestier E, Heyman M, Andersen MK, Autio K, Blennow E, et al (2008) Outcome of ETV6/RUNX1-positive childhood acute lymphoblastic leukaemia in the NOPHO-ALL-1992 protocol: frequent late relapses but good overall survival. Br J Haematol 140(6): 665-672.

[6]. Ney-Garcia DR, Liehr T, Bhatt S, de Souza MT, de Matos RR, et al. (2012) Molecular cytogenetics studies reveal unexpected chromosomal inversion as variant of $\mathrm{t}(12 ; 21)(\mathrm{p} 13 ; \mathrm{q} 22)$ in child with B-cell precursor acute lymphoblastic leukemia. Leuk Lymphoma 53(2): 342-344. 